\title{
Analysis of Closed Loop control of Cascaded Three Phase Grid Tied Inverter using Fuzzy Logic Controller
}

\author{
V. Krishna Chaithanya ${ }^{1}$, A. Pandian ${ }^{2}$, RBR Prakash ${ }^{3}$, Ch. Rami Reddy ${ }^{4}$ \\ ${ }^{1,2,3}$ Dept. of Electrical and Electronics Engineering, Koneru Lakshmaiah Education Foundation, Guntur, India. \\ ${ }^{4}$ Dept. of Electrical and Electronics Engineering, Nalanda Institute of Engineering and Technology, Guntur, India. \\ vkrishnachaithanya@gmail.com
}

\begin{abstract}
Bidirectional power transfer can be achieved in DC/AC systems by using cascaded converters. The topology of Dual Active Bridge Cascaded with Inverter (DABCI) is used in this paper. A closed-loop control scheme is implemented for the Six Pulse Modulation (SPM) technique for pulses to the inverter. This SPM technique can increase the DC bus utilization and also reduces the switching frequency of the inverter to $33 \%$ when compared to normal PWM techniques. The Fuzzy logic controller is used for reducing Total Harmonic Distortion (THD) and dc-link utilization is improved. Comparison between the PI controller and the fuzzy logic controller is analyzed.
\end{abstract}

Key words: Dual Active Bridge cascaded with inverter (DABCI), Six-Pulse Modulation (SPM), Total Harmonic Distortion (THD), Pulse Width Modulation (PWM).

\section{INTRODUCTION}

A DC to 3-ph AC interface is commonly used for various applications such as UPS, EV, grid integration of renewable energy sources and microgrids. In all these applications converters must have good efficiency, reliability, high power and bidirectional power flow. A DC converter cascaded with inverter is a perfect converter for the above-mentioned requirements [1], [2].

EV either with a fuel cell, battery or hybrid are environment friendly and efficient with low emission when compared to conventional vehicles i.e. internal combustion engines. Due to inadequate storage in electric vehicles, research has been done to advance the energy storage technology and propulsion architectures of EV. In spite of various converters available, Dual Active Bridge (DAB) converter is mostly preferred converter for integrating $\mathrm{EV}$ to the grid. $\mathrm{DAB}$ is mainly preferred because of its bidirectional power flow, with symmetrical structure, soft switching and high-power density [3], [4]. So, this converter is preferred for cascading with an inverter.

PWM techniques such as Space Vector Modulation (SVM), Sine Pulse Modulation are commonly used in 3-ph voltage source Inverter (VSI). By using some latest modulation techniques such as discontinuous PWM and with bus clamping, one can realize switching frequency reduction up to $33 \%$. But for further reduction of switching frequency Six Pulse Modulation technique (SPM) has to be preferred [5], [6]. In this technique one leg of the inverter switches are switched at high frequency [7] but whereas the other legs of the inverter will be connected to the dc link. So, the combination of varying DC bus capacitor and clamping two legs to dc bus will reduce switching losses up to $87 \%$ at unity power factor. So, SPM modulated DABCI with PI controller as dc-link controller is presented in [8]. Since the PI controller is having high settling time and large steady state error, fuzzy logic controller is implemented in this paper. SPM technique with a single reference is presented in [9].

Coordinated control of VSI \& DAB is done in this paper because it is essential for controlling the grid tied DABCI [10].

The main objectives of this paper are

- Analysis of DAB converter

- Control scheme for implementing SPM modulation for pulses to the inverter and DAB.

- Comparative study of controlling dc-link using Fuzzy logic controller and PI controller

This paper is planned as follows: DAB converter and SPM technique discussed in Section $\square$. Section $\square$ discusses closed loop control of DABCI. In Section $\square$ the dc-link controller used in this paper is explained. In Section $\square$ simulation results are presented.

\section{SPM MODULATED DABCI}

\subsection{Dual Active Bridge}

The whole converter involves a Dual Active Bridge converter which supplies a pulsating dc bus that is cascaded to a 3-ph VSI as shown in Figure. 1 [8]. The DAB is a Bidirectional, controllable DC-DC converter having high power capabilities which includes a primary side and secondary side semiconductor bridges with 8 semiconductor devices, a high frequency transformer energy transfer element and couple of dc-link capacitors. Because of symmetry of this converter i.e. same primary and secondary converters, it is capable of achieving bidirectional power flow which is one of the main reasons of selecting this converter for smart green power mode applications. 


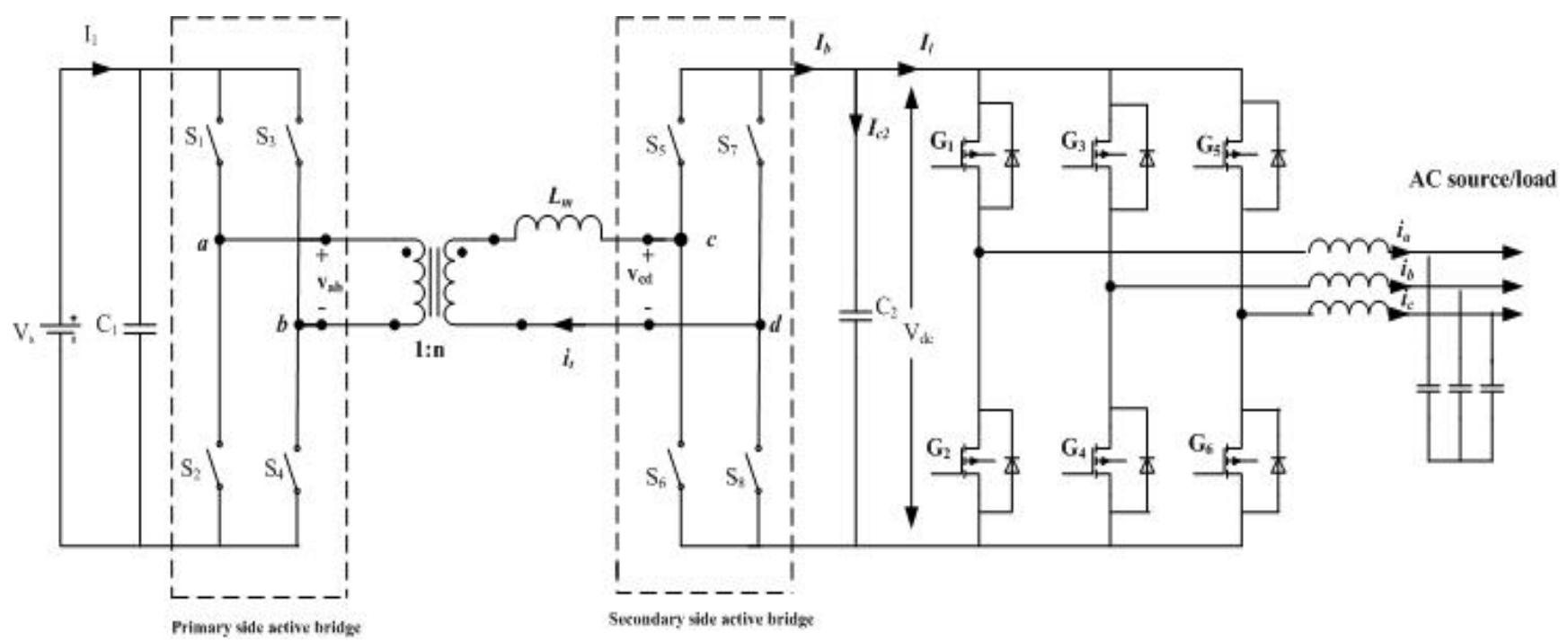

Figure 1: Schematics of DABCI

The topology is shown in Figure. 1 , where $V_{i}$ and $V_{d c}$ are dc-link voltages, $L_{m}$ is series leakage inductance for energy transfer, $S_{1-8}$ are controllable semiconductor switches and $C_{1}, C_{2}$ are dc-link capacitors. When these two active bridges present on primary and secondary sides are switched ON, it generates two square wave voltages $V_{a b}$ and $V_{c d}$. By controlling the phase shift of the two voltages, power flow will be controlled. If leading phase shift is maintained between $V_{a b}$ and $V_{c d}$ i.e., $V_{a b}$ is leading with respect to $V_{c d}$, the power transfer will be from DC source to the load. Similarly, if lagging phase shift between $V_{a b} \& V_{c d}$ i.e., $V_{c d}$ is lagging with respect to, the power transfer will be from load to dc source

\subsection{SIX PULSE MODULATION TECHNIQUE}

Commonly used PWM technique for a VSI generates converter terminal voltage with respect to the reference voltage given to modulator. If PWM techniques like SVM and SPM are to be implemented on a converter the dc-link voltage should be constant. In this case the converter is used for maintaining dc-link voltage constant but it is not at all involved in implementation of PWM. But in case of SPM, the maximum value of $\mathrm{AC}$ reference voltages is tracked by the dc bus voltage that are connected to the modulator. The voltage control loop and DAB are used to realize this. The dc bus voltage controller varies the phase shift of DAB in such a way that the dc-link voltage $\left(V_{d c}\right)$ is the maximum value of line to line of the voltage reference. In such a way DAB and VSI are dynamically coordinated for implementing SPM.

The total time period of the given reference phase voltage is divided into 6 sections. These 6 sections allocate with $60^{\circ}$ phase difference and change gradually from section 1 to section 6 equivalent to the line- line voltage RMS value. The modulation index for each leg is selected with respect to the operating section. The modulation index for each section is tabulated in Table 1. Switching pulse for one of the inverter switches (G1) is shown in Figure. 2[8].

Table 1: Inverter switching States

\begin{tabular}{|c|c|c|c|c|c|c|}
\hline \multirow{2}{*}{$\begin{array}{l}\text { Modulation } \\
\text { Index }\end{array}$} & \multicolumn{7}{|c|}{ Section } \\
\cline { 2 - 7 } & $\mathbf{1}$ & $\mathbf{2}$ & $\mathbf{3}$ & $\mathbf{4}$ & $\mathbf{5}$ & $\mathbf{6}$ \\
\hline$m_{1}$ & 1 & $\frac{V_{a c}}{V_{b c}}$ & 0 & 0 & $\frac{V_{a b}}{V_{c b}}$ & 1 \\
\hline$m_{2}$ & $\frac{V_{b c}}{V_{a c}}$ & 1 & 1 & $\frac{V_{b a}}{V_{c a}}$ & 0 & 0 \\
\hline$m_{3}$ & 0 & 0 & $\frac{V_{c a}}{V_{b a}}$ & 1 & 1 & $\frac{V_{c b}}{V_{a b}}$ \\
\hline
\end{tabular}

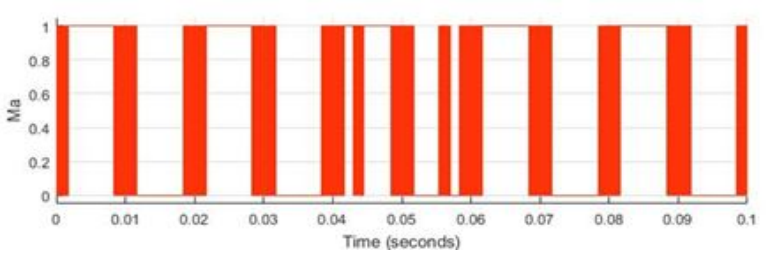

Figure 2: Switching pulse for inverter switch (G1)

\section{CLOSED-LOOP CONTROL SCHEME FOR IMPLEMENTING SPM}

Controlling a SPM modulated inverter that is connected to the grid is different from conventional methods like SVM modulation and Sine pulse modulation. In all these conventional modulation techniques, phase and frequency of grid voltage are obtained by a synchronous frame with Phase Locked Loop (PLL).

The control block of DABCI in shown in Figure. 3[8]. A current loop controller is executed in synchronous frame that controls the power flow between the AC and DC. In the block diagram $I_{d}$ is the direct axis component and $I_{q}$ is the quadrature component of the grid current. The power transfer is controlled by selecting the respective references $I_{d}^{*} \& I_{q}^{*}$ which are the reference components of grid current. The selection these reference currents for drawing or injecting constant active power is done as follows [11]. 


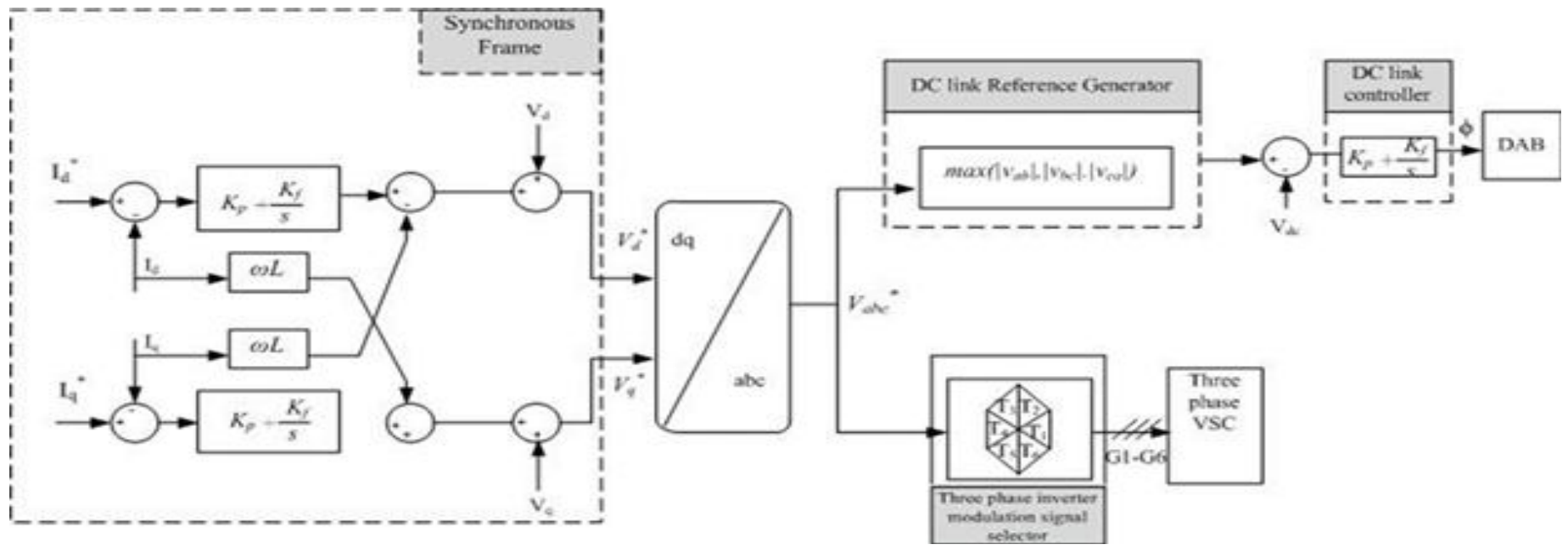

Figure 3: Control block diagram of DABCI

$\left[\begin{array}{c}I_{d}^{p^{*}} \\ I_{q}^{p^{*}} \\ I_{d}^{n^{*}} \\ I_{q}^{n^{*}}\end{array}\right]=\frac{-2 P_{0}^{*}}{3 D}\left[\begin{array}{c}V_{d}^{p} \\ V_{q}^{p} \\ -V_{d}^{n} \\ -V_{q}^{n}\end{array}\right]$

$D=\left[\left(V_{d}^{p}\right)^{2}+\left(V_{q}^{p}\right)^{2}\right]-\left[\left(V_{d}^{n}\right)^{2}+\left(V_{q}^{n}\right)^{2}\right]$

Where $V_{d}^{p}, V_{q}^{p}, V_{d}^{n}, V_{q}^{n}$ are components of grid voltage with positive and negative sequence which are stated in direct and quadrature components respectively, $P_{0}^{*}$ is power reference. The references $V_{d}^{*}, V_{q}^{*}$ gained from current control loop are transformed into 3 -phase reference voltages. From these reference voltages, reference voltage for the dc-link controller and pulses for inverter are obtained. Thus, dc-link voltage is coordinated with switching of the inverter which is essential for the implementation of SPM. The inverter modulation signal selector selects the modulating signals for the inverter from Table 1 and are compared with a carrier pulse which in this case is a triangular wave for generating pulses to the inverter.

The grid voltage is mentioned in unbalanced conditions because the 3-ph grid voltages become unbalanced when there is grid failure or asymmetrical loading. So, the selected converter has to work in unbalanced conditions. The 3-ph active power is constant during balanced load but in case of unbalanced load the active power will have second order harmonic oscillations because of interface between the components of voltage and current i.e. positive and negative sequences. The normal dq frame will not assure the efficient performance under unbalanced load conditions. So, for achieving control over these components a current controller is added.

\section{FUZZY LOGIC CONTROLLER}

In PI controller, the settling time will be very high and will have large steady state error. The dc link utilization is also low when compared to other controllers. So, in order to overcome these issues Fuzzy Logic Controller (FLC) is used in this paper. Technically, FLC is one of the most important software-based techniques.

The selected inputs are error range of dc-link voltage and change in DC-link voltage error. Membership function used is triangular membership function and centroid method is used for defuzzification. The inputs such as voltage error and change in voltage error are expressed in fuzzy sets with variables denoted as Very Low (VL), Low(L), Medium(M), High $(\mathrm{H})$, Very High $(\mathrm{VH})$. Since there are 5 variables for each input 25 rules are formed. The rules are written with if-then statements. The inputs are related with logical operator AND. AND logic produces the output as minimum value of inputs. The fuzzy rule base is tabulated in Table 2, and input membership functions are presented in Figure. 4
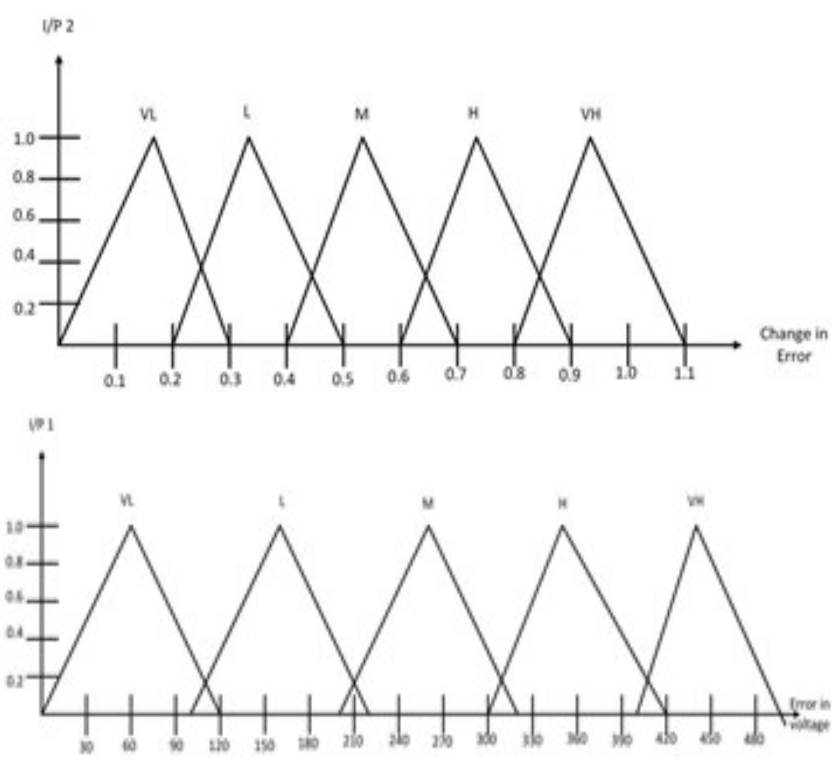

Figure. 4: Membership function for inputs 1 (DC-link voltage error) $\& 2$ (change in error) 
Table 2 Fuzzy rule base

\begin{tabular}{|c|c|c|c|c|c|}
\hline \multirow{2}{*}{ INPUT 1 } & \multicolumn{5}{|c|}{ INPUT 2 } \\
\cline { 2 - 6 } & $\begin{array}{c}\text { Very } \\
\text { Low }\end{array}$ & Low & Medium & High & $\begin{array}{c}\text { Very } \\
\text { High }\end{array}$ \\
\hline Very Low & VL & VL & VL & VL & VH \\
\hline Low & VL & L & L & H & VH \\
\hline Medium & VL & M & M & H & VH \\
\hline High & VL & H & H & H & VH \\
\hline Very High & VL & VH & H & H & VH \\
\hline
\end{tabular}

\section{SIMULATION RESULTS}

The proposed DABCI system is tested under two cases i.e. using PI controller and by using Fuzzy logic Controller and verified the test results. Fig. 5 shows simulation results of the proposed DABCI using PI controller. The controller tracks the change in the reference voltage without causing any change in the dc voltage. In case 1 i.e., while using PI controller, FFT analysis is carried out and $1.40 \%$ THD is obtained for the Grid Current. Fig. 7 shows the dc link Voltage and Current when PI controller is used. Fig. 8 shows simulation results of DABCI using Fuzzy logic controller. In case 2 i.e., while using Fuzzy controller, FFT analysis is carried out and $0.59 \%$ is obtained for the Grid current.

Case 1: Proposed DABCI using PI Controller

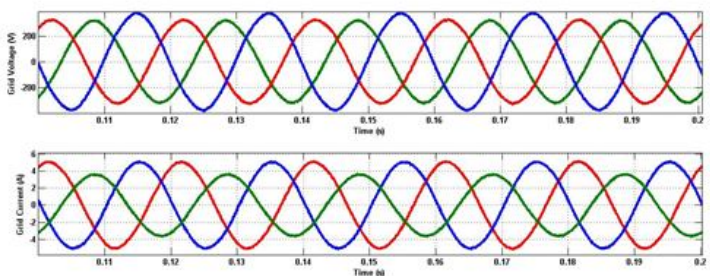

Figure 5: Simulation results showing Grid voltage and Grid current

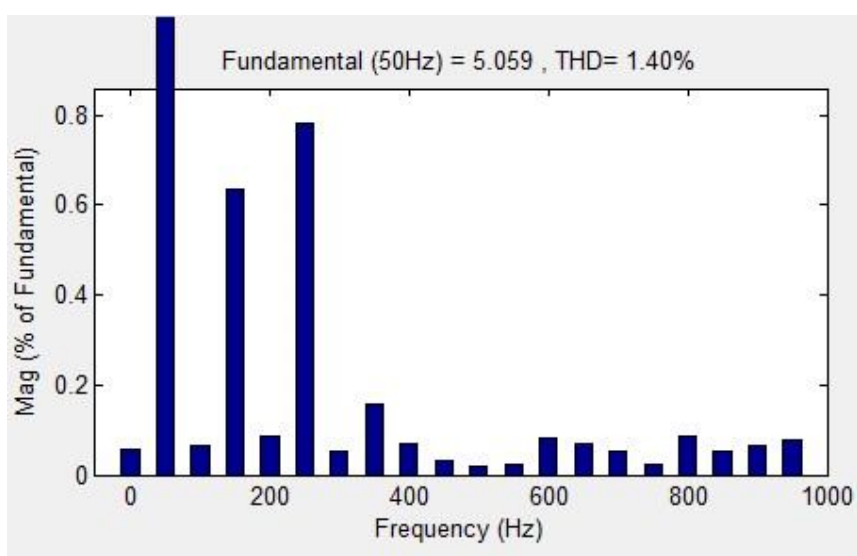

Figure 6: THD of Grid current with PI controller

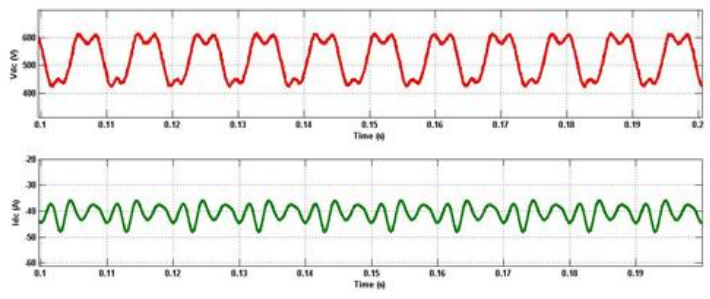

Figure 7: DC-Link voltage and current with PI controller
Case 2: Proposed DABCC with Fuzzy Controller
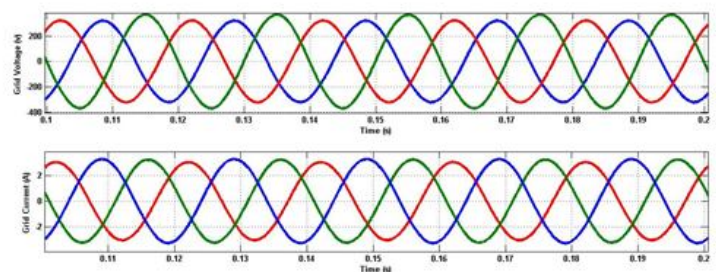

Figure 8: Simulation results showing Grid voltage and Grid current

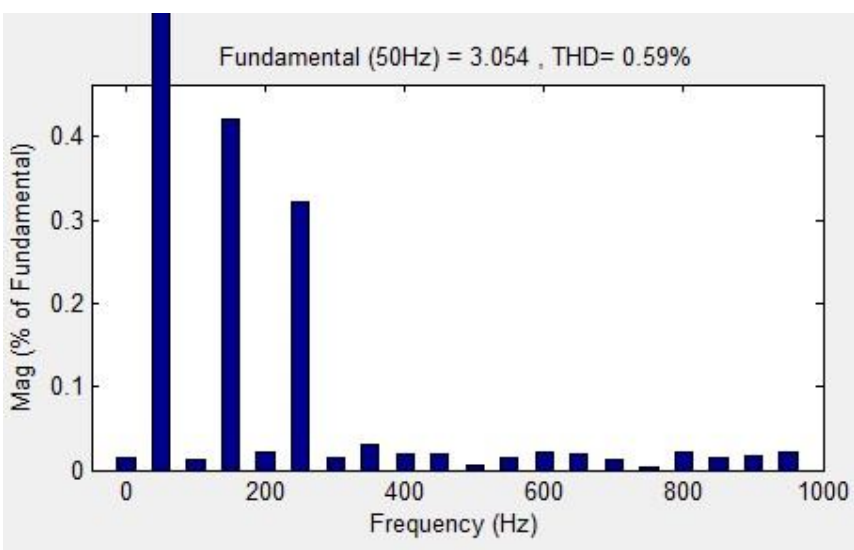

Figure 9: THD analysis of Grid Current using Fuzzy logic controller

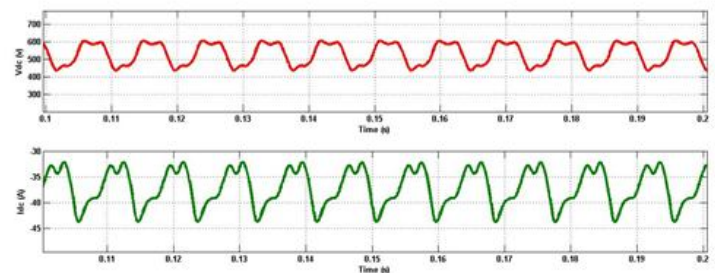

Figure. 10: DC-link voltage and current with Fuzzy logic controller

\section{CONCLUSION}

A fuzzy and PI based control scheme is effectively implemented for SPM based bidirectional converter connected to the grid. A closed loop control scheme to implement SPM through which pulses are given to both DAB \& VSI is presented. From the simulation results it is observed that by using fuzzy logic controller grid current's THD is reduced from $1.4 \%$ to $0.59 \%$.

\section{REFERENCES}

1. S. Bekiarov and A. Emadi, Uninterruptible power supplies: Classification, operation, dynamics and control in proc.Appl. Power Electron.Conf. Expo.,2002, pp. 597-604

2. M. Abusara, J. Guerrero, and S. Sharkh, Line-interactive UPS for microgrids IEEE Trans. Ind. Electron., vol. 61, no. 3, pp. 1292-1300, Mar. 2014. https://doi.org/10.1109/TIE.2013.2262763

3. Y. Tian, Z. Chen, F. Deng, X. Sun, and Y. Hu, Active power and DC voltage coordinative control for cascaded DC-ac converter with bidirectional power application IEEE Trans. Power Electron., vol.30, no. 10, pp.5911-5925, Oct. 2012 
https://doi.org/10.1109/TPEL.2014.2375573

4. Y. Tian, Z. Chen, F. Deng, X. Sun, and Y. Hu, DC-link voltage coordinated-proportional control for cascaded converter with zero steady state error and reduced system type IEEE Trans. Power Electron., vol. 31, no. 4, pp. 3177-3188, Apr. 2016. https://doi.org/10.1109/TPEL.2015.2444386

5. G. Narayanan, H.K. Krishnamurthy, D. Zhao, and R. Ayyanar, Advanced bus-clamping PWM Techniques based on space vector approach IEEE Trans. Power Electron., vol. 21, no. 4, pp. 974-984, Jul. 2006. https://doi.org/10.1109/TPEL.2006.876854

6. Q. Lie and F.Z. Peng, Space vector pulse width amplitude modulation for a buck boost voltage/current source inverter IEEE Trans. Power Electron., vol. 29, no.1, pp. 266-274, Jan. 2014. https://doi.org/10.1109/TPEL.2012.2225847

7. U. Prasanna and A.K. Rathore, Dual three pulse modulation based high frequency pulsating DC link two stage three phase inverter for electric/hybrid/fuel cell vehicles applications IEEE J. Emerg. Sel.Topics Power Electron., vol. 2, no. 2, pp. 477-486, Sep. 2014. https://doi.org/10.1109/JESTPE.2014.2304472

8. V.K. Kanakesh, Dorai Babu Yelavarthi Analysis and Implementation of Closed loop control of Electrolytic Capacitor-less Six pulse DC-link Bidirectional three phase grid tied inverter IEEE Trans. On Industrial applications, vol. 54, no. 1, Jan/Feb 2018. https://doi.org/10.1109/TIA.2017.2757438

9. U. Prasanna and A.K. Rathore, A novel single reference six pulse modulation (SRSPM) technique based interleaved high frequency three phase inverter for fuel cell vehicles IEEE Trans.Power Electron., vol.28, no.12, pp.5547-5556, Dec. 2013. https://doi.org/10.1109/TPEL.2013.2258405

10. V.K. Kanakesh, A. Ghosal, D.B. Yelavarthy, A.K. Rathore, and R. Mahanty, High frequency six pulse DC link based bidirectional three phase inverter without intermediate decoupling capacitor in Proc. IEEE Energy Convers. Congr. Expo., Milwaukee, WI, USA, Sep. 18-22, 2016, pp. 1-8. https://doi.org/10.1109/ECCE.2016.7855161

11. Meera Sharma, Parag Nijhawan, Amrita Sinha, Role of Battery Energy Storage System in Modern Electric Distribution Networks - A Review International journal of advanced trends in computer science and engineering, vol.8, no.3, pp:443-450, 2019. https://doi.org/10.30534/ijatcse/2019/18832019

12. Y. Suh, Y. Go, and D. Rho A Comparative study on control algorithm for active front end rectifier of large motor drives under unbalanced input IEEE Trans. Ind.Appl., vol. 47, no. 3, pp. 825-835, May/Jun. 2011. https://doi.org/10.1109/TIA.2011.2126015

13. Parag Nijhawan, Amandeep Singh Oberoi, An Innovative Design of a Solar-Wind Hybrid System International journal of advanced trends in computer science and engineering, vol.8, no.2, pp:203-207, 2019 https://doi.org/10.30534/ijatcse/2019/15822019

14. Jarupalli Somlal, M. Venu Gopal Rao, FUZZY logic-based space vector PWM controlled hybrid active power filter for power conditioning WSEAS Trans. on power systems, vol. 9, pp. 242-248, Jan. 2014.

15. F. Krismer, Modeling and optimization of bidirectional dual active bridge DC-DC converter topologies Ph.D. dissertation, Dept. Inform. Tech. Elect. Eng., ETH Zrich, Zurich, Switzerland, 2010.

16. V. Qin and J. W. Kimball, Generalized average modeling of dual active bridge DC-DC converter IEEE Trans. Power Electron., vol. 27, no. 4, pp. 2078-2084, Apr. 2012.

https://doi.org/10.1109/TPEL.2011.2165734

17. M. Salcone and J. Bond, Selecting film bus link capacitors for high performance inverter applications in Proc. IEEE Elect. Mach. Drives Conf., May 2009, pp. 1692-1699.

https://doi.org/10.1109/IEMDC.2009.5075431 